\title{
Signo de la botella de Coca-Cola
}

\section{Coke-bottle sign}

\author{
MC Ortega Hrescak ${ }^{1} \quad$ MJ Marañón ${ }^{2} \quad$ MS Diaz Terraf ${ }^{1} \quad$ RC Mohana $^{1} \quad$ M Palavecino $^{1}$
}

1 Instituto GAMMA, Maipú 747, San Miguel de Tucumán, Tucumán, Argentina

${ }^{2}$ CPC - Consultorio de Endocrinología, Rivadavia 550, San Miguel de Tucumán, Tucumán, Argentina

Rev Argent Radiol 2019;83:133-135.

El signo de la botella de Coca-Cola, también llamado Coke Bottle sign, se refiere al hallazgo producido por el aumento del espesor de los músculos extraoculares (MEO), siendo máximo en la porción media, con preservación relativa de las inserciones tendinosas en el globo ocular y en el vértice orbitario (-Fig. 1). ${ }^{1}$

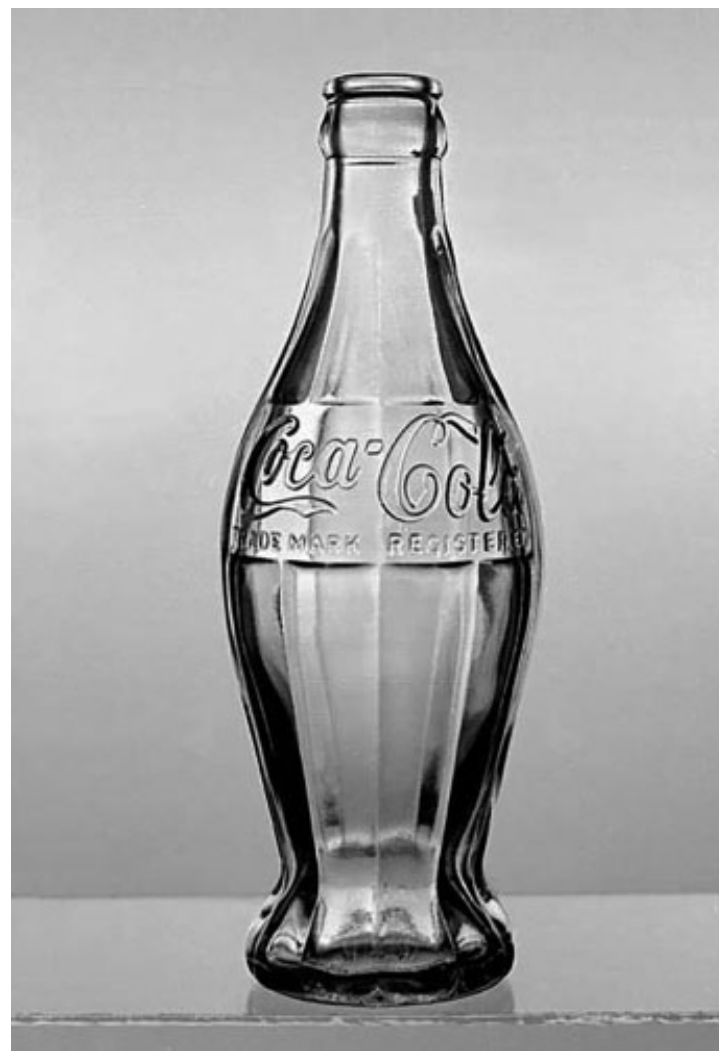

Fig. 1 Botella de Coca-Cola de 1915, patentada por Root Glass Company de Terre Haute, Indiana, Estados Unidos.

received

April 28, 2018

accepted

May 21, 2019
DOI https://doi.org/

10.1055/s-0039-1692692. ISSN 1852-9992.
Address for correspondence Cinthya Ortega Hrescak, MD, PhD, Marcos Paz 623, San Miguel de Tucumán, Tucumán, Argentina (e-mail: cinthya_ortega@hotmail.com.ar).

Otros autores atribuyen tal signo al incremento de grasa intra y extraconal improntando y abombando hacia medial la lámina papirácea del etmoides, con el perfil característico de la botella de Coca-Cola ( Figs. 2 a, 2 b) ${ }^{2}$

Debido al engrosamiento fusiforme de los MEO, ese signo se hace presente como la estilizada botella de Coca-Cola (llamada Coke en inglés) por la que es reconocida, siendo la bebida gaseosa más vendida mundialmente. $^{3}$ En 1914 , Coca-Cola retó a las compañías vidrieras de Estados Unidos a desarrollar una botella tan distintiva que "se reconociera al sentirla en la oscuridad o simplemente estando hecha pedazos en el suelo", que fue lanzada en $1915 .^{3}$

Basado en la revisión de la literatura, se desconoce hasta el momento quién describió ese signo por primera vez.

El signo en cuestión se asocia con frecuencia a la orbitopatía tiroidea (OT) o enfermedad de Graves, producida por el factor estimulante de la tiroides de acción prolongada (LATS). Es frecuente en adultos, con predominio en sexo femenino (4:1). Histológicamente existe: deposición de mucopolisacáridos, glicoproteína (etapa temprana) y colágeno (etapa tardía); infiltración de mastocitos y linfocitos, edema fibra muscular, necrosis, lipomatosis, degeneración grasa. Todo eso conlleva el aumento de volumen de los MEO. ${ }^{1}$

Los MEO suelen presentar afección bilateral entre el 70 y el $85 \%$ de los casos, siendo los más afectados el recto inferior, seguido por el recto medial. ${ }^{1}$

El diagnóstico de la OT se basa en los signos y síntomas oculares típicos, la evidencia de autoinmunidad tiroidea y la exclusión de otras patologías orbitarias, ya que ninguno de los signos oculares es específico. Normalmente, el diagnóstico de OT es evidente, debido al aspecto simétrico bilateral (70-85\%) de la OT en pacientes con antecedentes de hipertiroidismo de Graves. ${ }^{1,2}$

\section{Copyright (๑) 2019, Sociedad Argentina de Radiología. Publicado por Thieme Revinter Publicações Ltda., Rio de

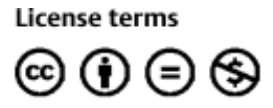
Janeiro, Brazil. Todos los derechos reservados. 


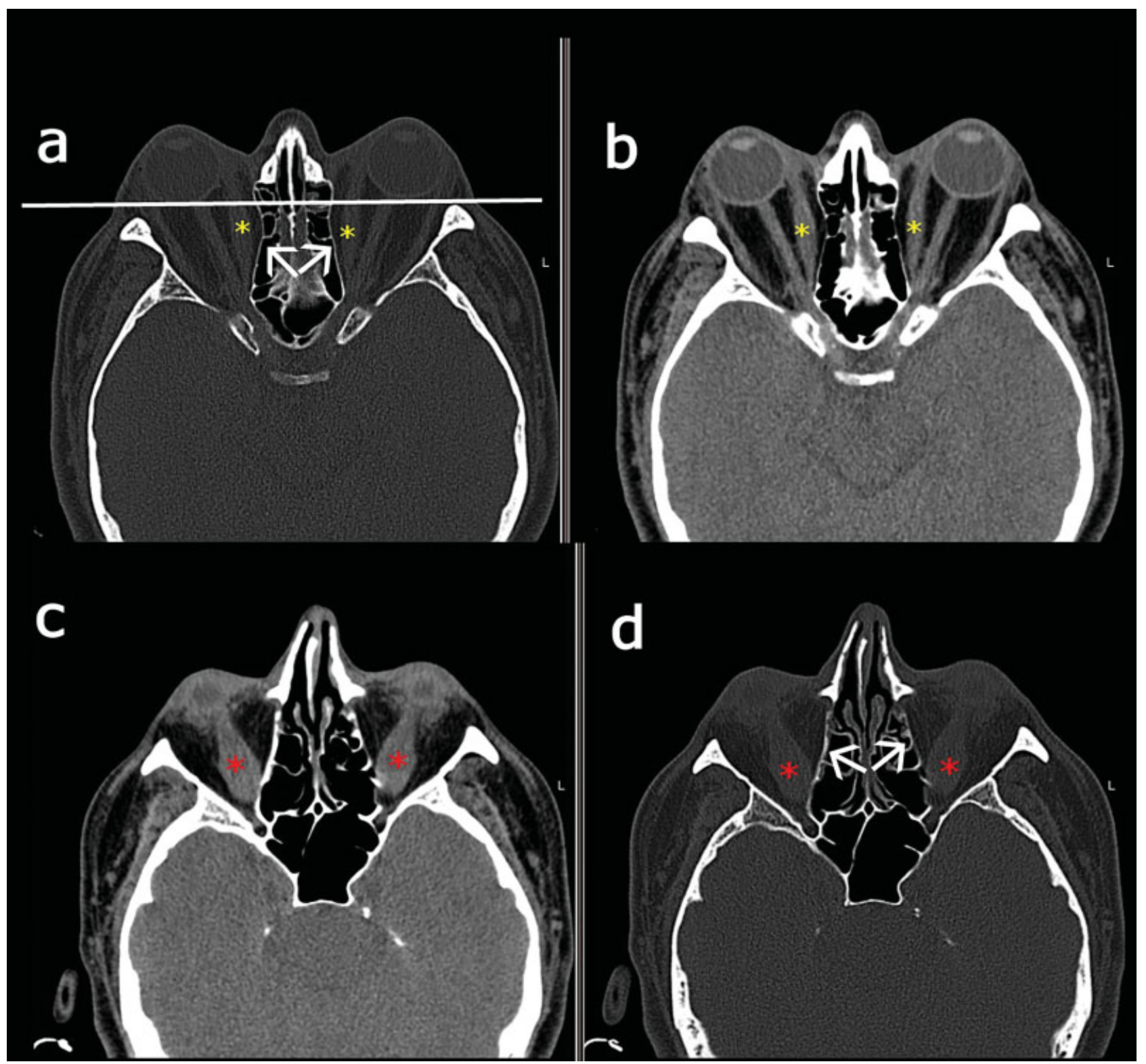

Fig. 2 TC de órbita (cortes axiales). Hombre de 34 años con OT. Ventana ósea (a y c): abultamiento con medialización de paredes mediales orbitarias (flechas). Existe proptosis del globo en las exploraciones axiales a nivel del cristalino con $<1 / 3$ del globo localizado detrás de la línea intercigomática (línea blanca). Ventana de partes blandas (b y d): muestra engrosamiento ahusado bilateral de bordes bien definidos de músculo recto medial (b) y recto inferior (d) mayor de $5 \mathrm{~mm}$, con preservación de la inserción muscular en el globo (asterisco).

Las manifestaciones clínicas típicas son: proptosis indolora uni/bilateral en adultos; retracción del párpado; edema periorbitario; inyección conjuntival; motilidad ocular restringida (se correlaciona con el aumento de los diámetros del MEO recto medio); neuropatía óptica progresiva (5\%) e hipertiroidismo (90\%). Los síntomas generalmente se desarrollan dentro de un año de la aparición del hipertiroidismo. ${ }^{1}$

Es importante distinguir la etapa inicial inflamatoria temprana de la enfermedad terminal fibrosa e inactiva. La etapa aguda se caracteriza por un edema intersticial de los MEO y los tejidos orbitarios, que responde a la inmunosupresión o radioterapia orbitaria. En la etapa final fibrótica, los MEO tienen cicatrices y no responden al tratamiento antiinflamatorio, por lo que es necesario un abordaje quirúrgico (-Fig. 3 ).

Los criterios de imagen morfológica sugestivos para OT en imágenes por resonancia magnética (IRM) y tomografía computada (TC) son un engrosamiento ahusado bilateral de bordes bien definidos de MEO múltiples mayores de $5 \mathrm{~mm}$, con relativa preservación de las inserciones tendinosas en el globo ocular y en el vértice orbitario, un aumento de densidad e incremento de la grasa intra y extraconal, ambos con abultamiento del tabique orbitario y proptosis del globo $>21 \mathrm{~mm}$ anterior a la línea intercigomática en las exploraciones axiales a nivel del cristalino $0<1 / 3$ del globo localizado detrás de la línea intercigomática. $^{1,2}$ 


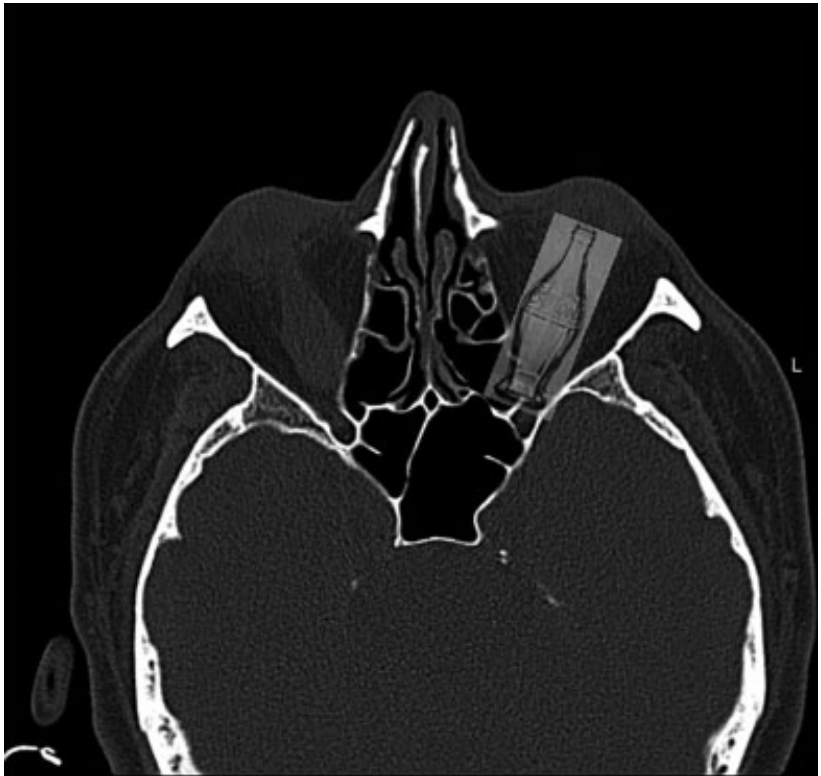

Fig. 3 TC orbitaria (corte axial): fusión de su músculo recto inferior izquierdo con imagen de botella de Coca-Cola.

Se consideran mediciones normales de MEO: músculo recto medial 4,1 $\pm 0,5 \mathrm{~mm}$; músculo recto inferior $4,9 \pm 0.8 \mathrm{~mm}$; músculo recto superior $3,8 \pm 0.7 \mathrm{~mm}$; músculo recto lateral $2,9 \pm 0.6 \mathrm{~mm}$; músculo oblicuo superior $2,4 \pm 0.4 \mathrm{~mm}^{1}$

La TC proporciona imágenes precisas de las estructuras periorbitales óseas, pero en la mayoría de los casos no revela información sobre la actividad de la enfermedad. ${ }^{2}$

La TC de órbita permite una alta resolución espacial de los tejidos blandos orbitales, sea con técnica helicoidal o multicorte, recomendándose esa última por su superioridad y vigencia hoy en día, con cortes de fino espesor $(0,6 \mathrm{~mm})$ para reformateo posterior multiplanar con cortes de $1 \mathrm{a} 3 \mathrm{~mm}$ de espesor, tanto en los ajustes de las ventanas óseas como de los tejidos blandos. La TC se utiliza como método adicional a la IRM para la planificación preoperatoria de las estructuras óseas, la descompresión guiada y el seguimiento después de la cirugía de descompresión. Las limitaciones son la exposición a la radiación del cristalino y una información bastante pobre sobre la etapa de la enfermedad. ${ }^{2}$

La IRM es la modalidad de elección para identificar cambios inflamatorios activos y evaluar cualquier respuesta de tratamiento inmunomodulador. La IRM siempre se requiere en casos dudosos como, por ejemplo, compromiso orbital asimétrico, para excluir cualquier otra patología orbital y la sospecha clínica de compresión del nervio óptico distiroideo en la orbitopatía de Graves. ${ }^{2}$
En etapa aguda, la IRM evidencia en secuencias ponderadas en T2WI y STIR a los MEO hiperintensos por edema, mostrando realce intenso de los mismos $\mathrm{y} / \mathrm{o}$ palpebral en secuencia ponderada en T1 con gadolíneo., ${ }^{1,2}$

En la etapa final fibrótica, los MEO presentan procesos cicatrizales, por lo que se evidencian hipointensos en secuencias ponderadas T1WI y T2WI, sin respuesta al tratamiento antiinflamatorio, siendo necesario un abordaje quirúrgico. $^{2}$

La enfermedad más frecuente (40\%) que imita la OT es la miositis orbitaria o pseudotumor orbitario, que cursa clínicamente con proptosis dolorosa, diplopía y edema orbital unilateral, y que radiológicamente puede involucrar cualquier MEO, los cuales presentan afección músculotendinosa. Los tendones de inserción del músculo están mal definidos y el periostio infiltrado. $1,2,4,5$

En conclusión, el signo de la botella de Coca-Cola permite un posible diagnóstico de OT y su diferenciación con el pseudotumor orbitario, incluso en pacientes eutiroideos o con clínica unilateral. Las reconstrucciones multiplanares en TCy IRM permiten la visualización de dicho signo en distintas proyecciones (axial y sagital).

\section{Confidencialidad de los datos}

Los autores declaran que han seguido los protocolos de su centro de trabajo sobre la publicación de datos de pacientes y que todos los pacientes incluidos en el estudio han recibido información suficiente y han dado su consentimiento informado por escrito.

\section{Conflicto de intereses}

Los autores declaran no tener ningún conflicto de intereses.

\section{Bibliografía}

1 Dahnert W. Orbit. In: Dahnert W, ed. Radiology Review Manual, 6th Ed. Philadelphia, PA: Lippincott Williams \& Wilkins; 2008: 331-340

2 Kirsch E, Hammer B, von Arx G. Graves' orbitopathy: current imaging procedures. Swiss Med Wkly 2009;139(43-44):618-623

3 Coca Cola Journey. Conoce la evolución de la botella de Coca-Cola en 100 años Web site. Disponible en: https://www.coca-colamexico. com.mx/conoce-la-evolucion-de-la-botella-de-coca-cola-en-100anos. Published Fbruery, 2015.

4 Boddu N, Jumani M, Wadhwa V, Bajaj G, Faas F. Not All Orbitopathy Is Graves': Discussion of Cases and Review of Literature. Front Endocrinol (Lausanne) 2017;8:184. Doi: 10.3389/ fendo.2017.00184

5 Lacey B, Chang W, Rootman J. Nonthyroid causes of extraocular muscle disease. Surv Ophthalmol 1999;44(03):187-213 